Supporting Information

\title{
Highly Efficient Catalytic Performances of Eco-Friendly Grown Silver Nanoshells
}

\author{
Jaewon Lee and Du-Jeon Jang* \\ Department of Chemistry, Seoul National University, NS60, Seoul 08826, Korea \\ E-mail: djjang@snu.ac.kr
}




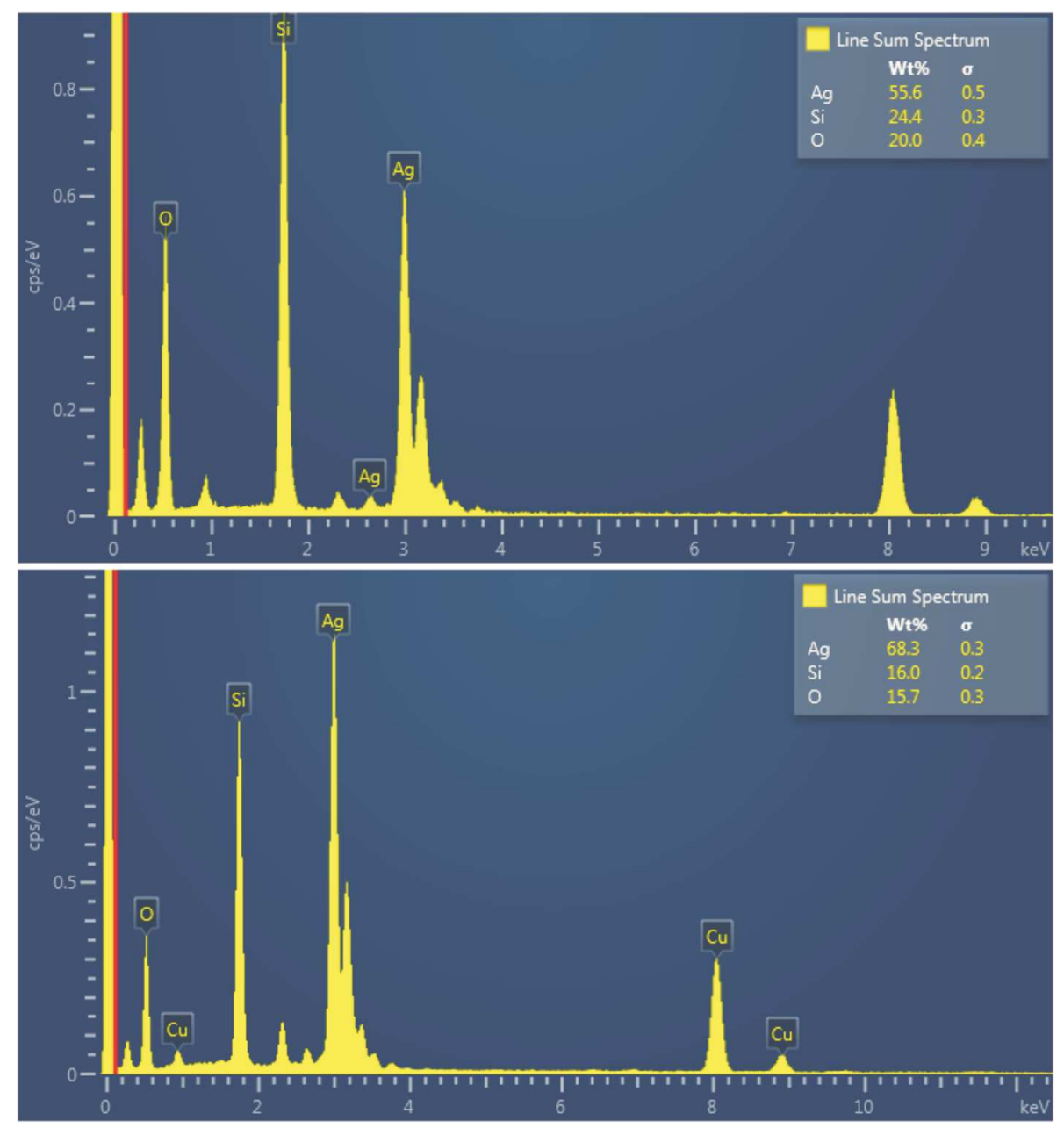

Figure S1. EDX analysis spectra of (top) $\mathrm{Ag} @ \mathrm{SiO}_{2} @ \mathrm{Ag}_{\mathrm{NPs}}$ and (bottom) $\mathrm{Ag} @ \mathrm{SiO}_{2} @ \mathrm{Ag}_{\mathrm{NPs}}-\mathrm{L}$, where the molar percentages of silver have been observed to be $55.6 \%$ and $68.3 \%$, respectively. 


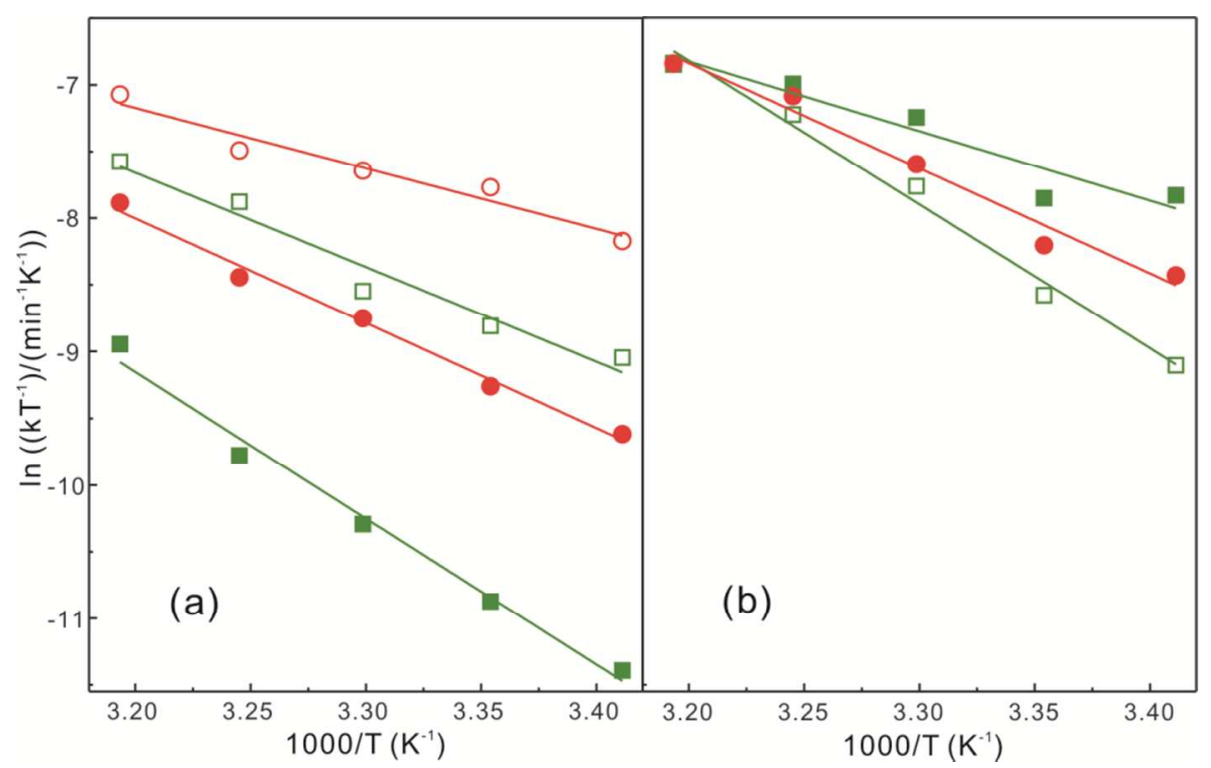

Figure S2. Eyring plots for the (a) $k_{1}$ and (b) $k_{2}$ catalytic-degradation rate constants of $\mathrm{RhB}$ in the presence of $\mathrm{KBH}_{4}$ via nanocatalysts of (closed squares) $\mathrm{Ag} @ \mathrm{SiO}_{2} @ \mathrm{Ag}_{\text {seeds, }}$, (open squares) $\mathrm{Ag} @ \mathrm{SiO}_{2} @ \mathrm{Ag}_{\text {seeds }}-\mathrm{L}$, (closed circles) $\mathrm{Ag} @ \mathrm{SiO}_{2} @ \mathrm{Ag}_{\mathrm{NPs}}$, and (open circles) $\mathrm{Ag} @ \mathrm{SiO}_{2} @ \mathrm{Ag}_{\mathrm{NPs}^{-}}$ L.

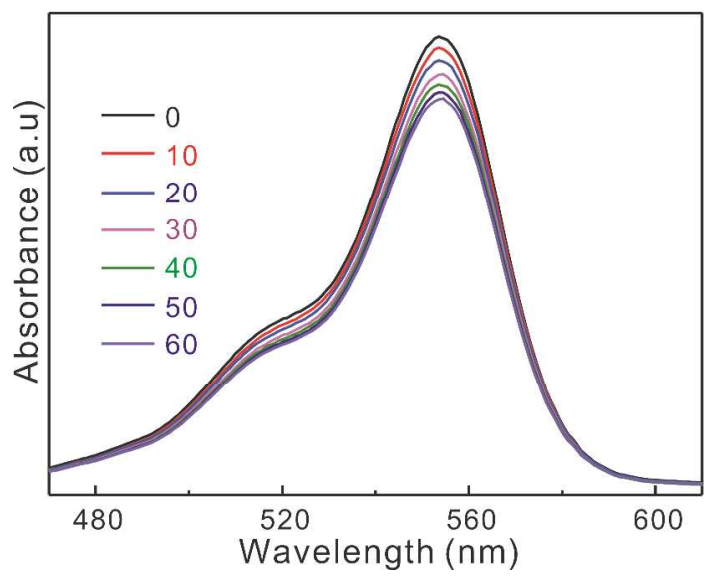

Figure S3. Absorption spectra at $30{ }^{\circ} \mathrm{C}$ of $\mathrm{KBH}_{4}$-added aqueous $\mathrm{RhB}$ solutions, measured at elapsed times indicated in the units of min in the absence of nanocatalysts. 